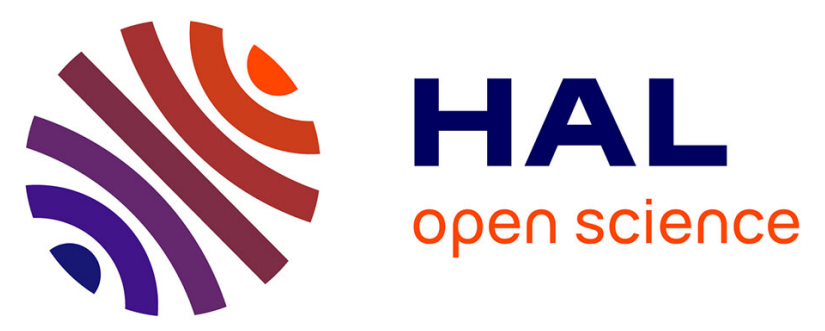

\title{
Implementation of probabilistic assessments to support the ASTRID decay heat removal systems design process
}

F. Aubert, B. Baude, P. Gauthe, M. Marquès, N. Perot, F. Bertrand, C. Vaglio-Gaudard, V. Rychkov, M. Balmain

\section{- To cite this version:}

F. Aubert, B. Baude, P. Gauthe, M. Marquès, N. Perot, et al.. Implementation of probabilistic assessments to support the ASTRID decay heat removal systems design process. Nuclear Engineering and Design, 2018, 340, pp.405-413. 10.1016/j.nucengdes.2018.09.002 cea-02429987

HAL Id: cea-02429987 https://hal-cea.archives-ouvertes.fr/cea-02429987

Submitted on 7 Jan 2020

HAL is a multi-disciplinary open access archive for the deposit and dissemination of scientific research documents, whether they are published or not. The documents may come from teaching and research institutions in France or abroad, or from public or private research centers.
L'archive ouverte pluridisciplinaire HAL, est destinée au dépôt et à la diffusion de documents scientifiques de niveau recherche, publiés ou non, émanant des établissements d'enseignement et de recherche français ou étrangers, des laboratoires publics ou privés. 


\title{
Implementation of probabilistic assessments to support the ASTRID decay heat removal systems design process
}

\author{
F. Aubert ${ }^{\mathrm{a}, *}$, B. Baude ${ }^{\mathrm{a}}$, P. Gauthé ${ }^{\mathrm{a}}$, M. Marquès ${ }^{\mathrm{a}}$, N. Pérot ${ }^{\mathrm{a}}$, F. Bertrand ${ }^{\mathrm{a}}$, C. Vaglio-Gaudard ${ }^{\mathrm{a}}$, \\ V. Rychkov ${ }^{\mathrm{b}}$, M. Balmain ${ }^{\mathrm{b}}$ \\ ${ }^{\text {a } C E A, ~ D E N, ~ D E R, ~ S E S I, ~ F-13108 ~ S a i n t-P a u l-l e z ~ D u r a n c e, ~ F r a n c e ~}$ \\ ${ }^{\mathrm{b}}$ EDF R\&D, 1 avenue du Général de Gaulle, 92141 Clamart Cedex, France
}

\section{A R T I C L E I N F O}

\section{Keywords:}

Probabilistic assessments

Sodium fast reactor

Decay heat removal

Static

Dynamic

\begin{abstract}
A B S T R A C T
ASTRID, the Advanced Sodium Technological Reactor for Industrial Demonstration, is a GenIV technological demonstrator. Its purpose will be to demonstrate the progress made in the field of Sodium Fast Reactor (SFR) technology on an industrial scale by qualifying innovative options, especially relative to safety and operability.

To support the ASTRID design process during the conceptual design phase, probabilistic assessments have been developed since 2012. They are based on the conventional Fault Tree (FT)/Event Tree (ET) approach and on the determination of the minimal decay heat removal (DHR) systems requirement. Limited to a period of one week, without repair of component malfunctions, their goal is to provide probabilistic insights in the assessment of various design choices and to supplement the deterministic approach in the objective of continuous safety improvements throughout the design process.

Nevertheless, the conventional FT/ET "static approach", developed for PWRs, appears to be inadequate for SFRs in the objectives of assessing the global risk and contributing to the demonstration of the practical elimination of the situation "loss of DHR function" for longer periods of time. Since DHR systems have to operate during long mission times, PSA modelling must consider the repair possibility, adapt the systems requirement to decay heat evolution and take into account all available systems at any time. Therefore, different dynamic probabilistic approaches are developed in a prospective way to comply with the safety demonstration. A first calculation will be performed by the end of the decade to support the demonstration of practical elimination of the DHR function of ASTRID.
\end{abstract}

\section{Introduction}

ASTRID, the GenIV Advanced Sodium Technological Reactor for Industrial Demonstration is a 1500 MWth pool-type Sodium-cooled Fast Reactor. Representative of the future high-powered industrial SFRs, it is developed in France with very high levels of requirements in the framework of an international program involving numerous partnerships (Gauché, 2013; Vasile, 2015).

ASTRID aims at qualifying innovative options relative to safety and operability, and at drawing lessons from French and international SFRs feedback (equivalent to a total of around 400 reactor years of operation, detailed per country in Table A1) (IRSN, 2015).
Table A1

SFRs repartition in the World [3].

\begin{tabular}{|c|c|c|c|}
\hline Country & Reactor name & Power & Operational period \\
\hline France & Rapsodie & $\begin{array}{l}25 \text { then } \\
40 \text { MWth, } \\
\text { non-power }\end{array}$ & From 1967 to 1982 \\
\hline France & Phenix & $\begin{array}{l}565 \text { MWth, } \\
250 \mathrm{MWe}\end{array}$ & From 1973 to 2009 \\
\hline France & Superphenix & $\begin{array}{l}3000 \text { MWth, } \\
1240 \mathrm{MWe}\end{array}$ & From 1985 to 1998 \\
\hline UK & $\begin{array}{l}\text { Prototype } \\
\text { Fast Reactor } \\
\text { (PFR) }\end{array}$ & $\begin{array}{l}650 \mathrm{MWth}, \\
250 \mathrm{MWe}\end{array}$ & From 1974 to 1994 \\
\hline
\end{tabular}

(continued on next page)

\footnotetext{
* Corresponding author.

E-mail address: florence.aubert@cea.fr (F. Aubert).
} 


\begin{tabular}{|c|c|c|}
\hline \multicolumn{3}{|c|}{ Nomenclature } \\
\hline AAR & Automatic reactor shutdown & \\
\hline ASEP & Accident Sequence Evaluation Program & \\
\hline ASTRID & $\begin{array}{l}\text { Advanced Sodium Technological Reactor for } \\
\text { Demonstration }\end{array}$ & Industrial \\
\hline CCF & Common Cause Failure & \\
\hline $\mathrm{CD}$ & Core Damage & \\
\hline $\mathrm{CDF}$ & Core Damage Frequency & \\
\hline CEA & $\begin{array}{l}\text { Commissariat à l'Energie Atomique et aux } \\
\text { Alternatives }\end{array}$ & Energies \\
\hline CRW & Control Rod Withdrawal & \\
\hline DHR & Decay Heat Removal & \\
\hline DHX & Decay Heat eXchangers & \\
\hline EDF & Electricité De France & \\
\hline ET & Event Tree & \\
\hline FT & Fault Tree & \\
\hline GET & Generic Event Tree & \\
\hline $\mathrm{I} \& \mathrm{C}$ & Instrumentation and Control & \\
\hline ID4 & Inadvertent Draining of the 4 secondary loops & \\
\hline IE & Initiating Event & \\
\hline
\end{tabular}

Table A1 (continued)

\begin{tabular}{|c|c|c|c|}
\hline Country & Reactor name & Power & Operational period \\
\hline Germany & KNK-1 & $\begin{array}{l}60 \text { MWth, } \\
\text { non-power }\end{array}$ & $\begin{array}{l}\text { Put into service in } \\
1972 \text {, retrofitted and } \\
\text { renamed KNK-2 in } \\
1977 \text {, and } \\
\text { permanently shut } \\
\text { down in } 1992\end{array}$ \\
\hline Germany & SNR-300 & $330 \mathrm{MWe}$ & $\begin{array}{l}\text { Began in } 1972 \text {, } \\
\text { abandoned in } 1991\end{array}$ \\
\hline Kazakhstan & BN 350 & $\begin{array}{l}750 \text { MWth, } \\
250 \mathrm{MWe}\end{array}$ & From 1972 to 1998 \\
\hline Russia & BOR-60 & $\begin{array}{l}60 \mathrm{MWth}, \\
12 \mathrm{MWe}\end{array}$ & Since 1968 \\
\hline Russia & $\mathrm{BN}-600$ & $\begin{array}{l}1470 \text { MWth, } \\
550 \text { MWe }\end{array}$ & Since 1980 \\
\hline US & EBR-II & $\begin{array}{l}62 \text { MWth, } \\
20 \text { MWe }\end{array}$ & From 1963 to 1993 \\
\hline US & FFTF & $\begin{array}{l}400 \text { MWth, } \\
\text { non-power }\end{array}$ & From 1980 to 1993 \\
\hline Japan & Joyo & $\begin{array}{l}140 \text { MWth, } \\
\text { non-power }\end{array}$ & $\begin{array}{l}\text { Achieved criticality in } \\
\text { 1994, operations } \\
\text { suspended since } 2007\end{array}$ \\
\hline Japan & Monju & $\begin{array}{l}714 \text { MWth, } \\
280 \text { MWe }\end{array}$ & $\begin{array}{l}\text { Achieved criticality in } \\
\text { 1994, forced to shut } \\
\text { down in } 1995 \\
\text { Restarted in } 2010 \text { but } \\
\text { stopped after an } \\
\text { accident and no } \\
\text { further authorization } \\
\text { to restart }\end{array}$ \\
\hline India & $\begin{array}{l}\text { FBTR (Fast } \\
\text { Breeder Test } \\
\text { Reactor) }\end{array}$ & $\begin{array}{l}40 \text { MWth, } \\
13 \text { MWe } \\
\text { (experimental) }\end{array}$ & Since 1985 \\
\hline China & $\begin{array}{l}\text { CEFR (China } \\
\text { Experimental } \\
\text { Fast Reactor) }\end{array}$ & $\begin{array}{l}60 \text { MWth, } \\
25 \text { MWe }\end{array}$ & $\begin{array}{l}\text { Connected to the grid } \\
\text { in } 2011 \text { and being } \\
\text { shutdown }\end{array}$ \\
\hline
\end{tabular}

Safety, among other goals declined in Table 1 (GIF, 2002), is at the heart of the GenIV project.

$\begin{array}{ll}\text { IEET } & \text { Initiating Event Event Tree } \\ \text { IHX } & \text { Intermediate Heat eXchanger } \\ \text { LOOP } & \text { Loss Of Off-site Power } \\ \text { MTTR } & \text { Mean Time To Repair } \\ \text { MDT } & \text { Mean Down Time } \\ \text { PCS } & \text { Power Conversion System } \\ \text { PP1 } & \text { Trip of 1 Primary Pump } \\ \text { PP3 } & \text { Trip of all 3 Primary Pumps } \\ \text { PSA } & \text { Probabilistic Safety Assessment } \\ \text { PWR } & \text { Pressurised Water Reactor } \\ \text { RRA } & \text { Active DHR system located into the vessel (in the cold } \\ & \text { pool) } \\ \text { RRB } & \text { Passive DHR system located into the vessel (in the hot } \\ & \text { pool) } \\ \text { RRC } & \text { Complementary DHR system through the reactor vault } \\ \text { SCL } & \text { Secondary Coolant Loop } \\ \text { SFR } & \text { Sodium Fast Reactor } \\ \text { SP4 } & \text { Trip of all 4 Secondary Pumps } \\ \text { SRS } & \text { Spurious Reactor Shutdown } \\ \text { WENRA } & \text { Western European Nuclear Regulators Association }\end{array}$

The 4th generation's SFRs are required to achieve an increased safety level, with advances on core and on sodium-related issues, and taking into account the lessons drawn from the Fukushima accident.

So, to improve the safety from the design level, the deterministic approach is completed by probabilistic studies (WENRA, 2013) which aim at:

- assessing design options and being confident in the good application of the deterministic design rules;

- demonstrating the practical elimination of the loss of DHR function among other situations (Michael Modro et al., 2017);

- verifying that the core damage frequency remains sufficiently low.

As France doesn't have any experience in performing probabilistic safety assessment for SFRs from the early design stage, CEA has developed a PSA strategy for ASTRID to comply with the main probabilistic objectives at the conceptual design level (Gauthé et al., 2012; Gauthé et al., 2013; Curnier et al., 2014). Probabilistic assessments are performed in partnership with FRAMATOME and EDF. Both of whom have a strong experience in the field not only of SFRs design and operation but also of PWR PSA. Furthermore, they will benefit from Japanese collaboration and feedback (Kubo et al., 2005; Yamano et al., 2012; Kurisaka, 2006; Kurisaka et al., 2014).

This paper will first discuss the PSA strategy before presenting probabilistic assessments performed to support the design process and to demonstrate the practical elimination of the loss of DHR systems.

\section{PSA implementation for ASTRID}

Probabilistic static assessments for ASTRID are being implemented during the different phases of the project represented in Fig. 1. It is important to point out that the early design stage, especially the preconceptual or conceptual design phase, is characterized by a lack of design and operational details and so, a lot of assumptions and conservatisms must cope with uncertainties in the modelling.

Probabilistic assessments were performed beginning in 2012 (after the first preliminary studies were launched in 2011) by means of the reference PSA tool, Risk-Spectrum ${ }^{\circledR}$ (Scandpower), used for French PWR PSA to complement deterministic approaches (Arrêté INB de février, 2012). Nevertheless, based on the methodology supported by FT/ET (NUREG-75/014, 1975), several limitations emerged (detailed in Section 4.2) in the assessment of the design and safety of SFRs. Therefore, dynamic probabilistic approaches have been under 
Table 1

. Goals for Generation IV Nuclear Energy Systems.

Goals for Generation IV Nuclear Energy Systems

Sustainability-1

Sustainability-2

Economics-1

Economics-2

Safety and Reliability-1

Safety and Reliability-2

Safety and Reliability-3

Proliferation Resistance and Physical

Protection
Generation IV nuclear energy systems will provide sustainable energy generation that meets clean air objectives and provides long-term availability of systems and effective fuel utilisation for worldwide energy production

Generation IV nuclear energy systems will minimise and manage their nuclear waste and notably reduce the long-term stewardship burden, thereby improving protection for the public health and the environment

Generation IV nuclear energy systems will have a clear life-cycle cost advantage over other energy sources

Generation IV nuclear energy systems will have a level of financial risk comparable to other energy projects

Generation IV nuclear energy systems operations will excel in safety and reliability

Generation IV nuclear energy systems will have a very low likelihood and degree of reactor core damage

Generation IV nuclear energy systems will eliminate the need for offsite emergency response

Generation IV nuclear energy systems will increase the assurance that they are very unattractive and the least desirable route for diversion or theft of weapons-usable materials, and provide increased physical protection against acts of terrorism development/validation since 2014 to deal with the necessity of long term calculations including repair considerations and on-line thermalhydraulic evaluations to demonstrate the practical elimination of the loss of the DHR function.

Based on the static PSA:

- the first phase (1) on Fig. 1) consisted in fault trees modelling, mainly dedicated to DHR systems studies: the reliability of the DHR function was studied from fault trees modelling of DHR systems and support systems on a time period of $100 \mathrm{~h}$. The objectives were to improve the consistency and reliability of the global DHR function design in terms of redundancy and diversification, and to demonstrate its conformity to the deterministic design rules. The fault trees for the reactor trip were also modelled, but in a basic way justified by focusing first on the DHR function;

- the second phase (2) on Fig. 1), taking on board design evolutions and a new reference configuration, has initiated the thinking on the determination of input data (mission times, decoupling criteria) and operational conditions to perform event trees modelling. It is more dedicated to checking the safety design balance, and to highlighting functional dependencies between safety systems.

Based on static and dynamic PSAs, the third phase (3) on Fig. 1) will be used:

- to evaluate the global level of safety of ASTRID by core damage frequency calculations (from static PSA for unprotected sequences and from dynamic PSA for others),

- to check the respect of probabilistic targets,

- and to contribute to the demonstration of practical elimination of the loss of the DHR function.

\section{Probabilistic assessments to support the design process}

The conventional probabilistic approach by FT/ET offers a complete model that integrates support systems and functional dependencies between systems. It is well adapted to sensitivity analysis and can be updated easily to follow the design evolutions. Therefore, this model was used first to provide design orientations for DHR systems from the safety standpoint (Curnier et al., 2014).

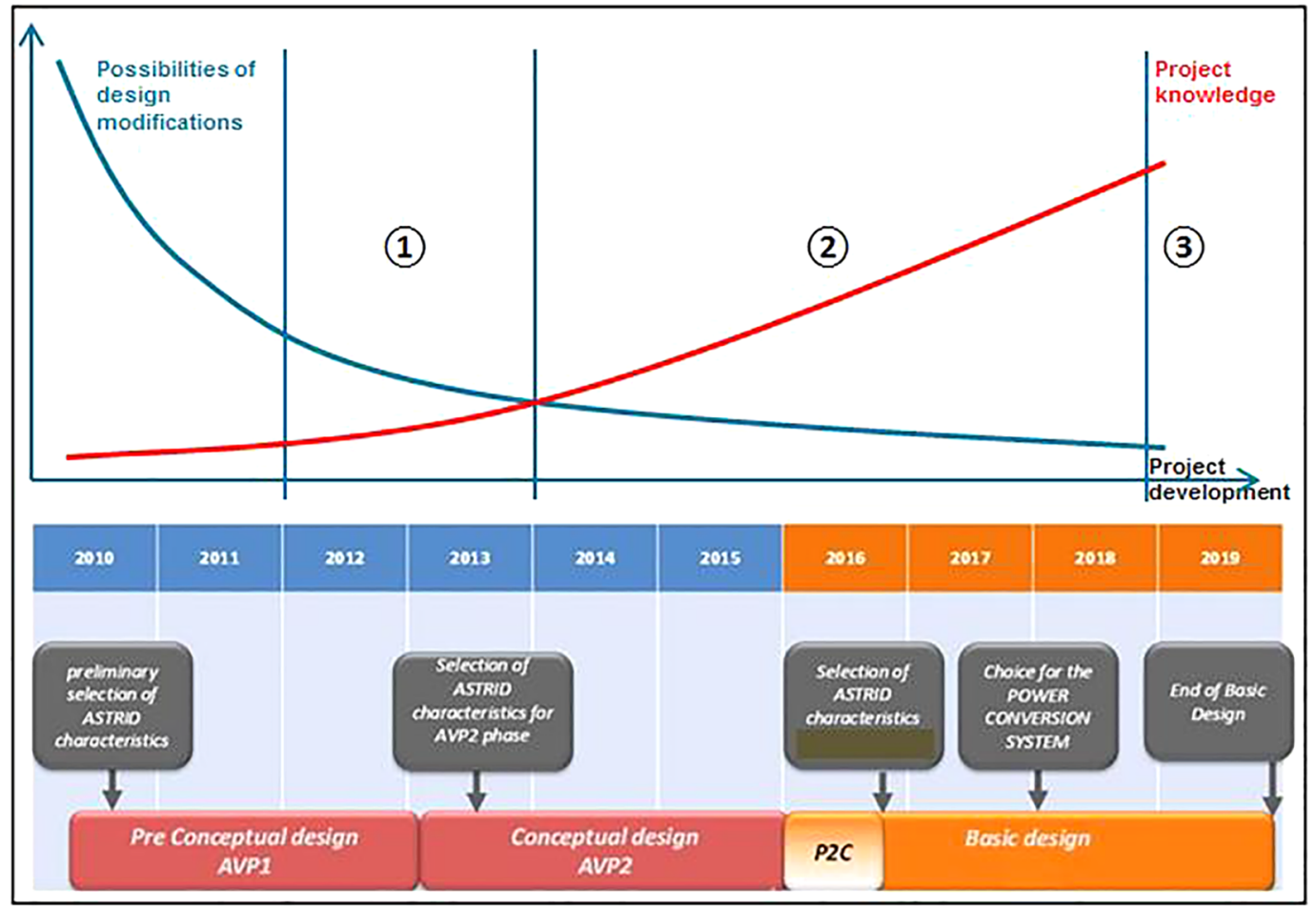

Fig. 1. Possibilities of design modifications according to the project knowledge during the project development. 


\subsection{Description of decay heat removal systems in the reference configuration for the conceptual design phase}

In ASTRID, the hot pool which contains the intermediate heat exchangers (IHX) inlets is separated by the inner vessel from the cold pool where the IHX outlets and the primary pumps inlets are located. The core sub-assemblies are located at the boundary between the hot and the cold pool. Three mechanical primary pumps are located in the cold pool to feed the core with cold sodium. After flowing through the core, the sodium leaves the hot pool via the inlet windows of the four IHX. In normal conditions, the secondary coolant loops (SCL) transfer the heat from the IHX to the Power Conversion System (PCS). The secondary coolant system comprises of four 375 MWth identical and independent sodium trains. After reactor shutdown, the decay heat can be removed through the SCL bypassing the turbine generator, for initiating events (IE) without impact on their operability. This option is not investigated in this study.

The decay heat removal relies on dedicated safety systems called RRA and RRB (each composed of two redundant trains and schematically represented in Fig. 2). RRA is located in the cold pool and RRB in the hot pool.

Each train of the RRA and RRB systems is a sodium loop extracting the primary sodium heat with a sodium/sodium Decay Heat eXchanger (DHX) and an air/sodium exchanger.

The two trains of RRB operate in natural convection on both sodium and air sides, while RRA trains operate in forced convection with electro-magnetic pumps. The physical separation, diversified design and operating modes of DHR systems are designed to eliminate common cause failures.

Another DHR system, RRC, is also investigated to complement the four DHX circuits. RRC is a diversified system operating through the reactor vault by means of an oil circuit.

Given its performances in the reference configuration described herein, RRC is a long term system which alone cannot remove the decay heat right after reactor shutdown.

\subsection{Static modelling}

\subsubsection{Objectives}

The objectives of the static modelling for ASTRID were:

- in the first phase (1): to improve the consistency and the reliability of DHR systems design in terms of redundancy and diversification;

- in the second phase (2): to determine input data and operational conditions, to check the balance between scenarios contributions and to highlight functional dependencies between safety systems;

- in the third phase (3: to assess the core damage frequency for unprotected sequences.

\subsubsection{Modelling description}

Static modelling is a complex and iterative task based on input structuring data definition, transient calculations, FT/ET modelling. The most structuring input data are:

- a decoupling criterion corresponding to the average primary sodium temperature, which must not exceed $650{ }^{\circ} \mathrm{C}$ in order to prevent thermal creep on the core support structures and on the primary vessel;

- a mission time limited to one week in order to compare design options on a period when repairs of failed components are not possible, which justifies no repair consideration.

The frequency (probability per year) of losing the DHR function on the whole period of requirement must be demonstrated to be as low as reasonably achievable.

The minimal combinations of the DHR systems required to achieve decay heat removal were evaluated by the simplified thermal-hydraulic code MODENA developed by the CEA (Gauthé et al., 2013) and based on the primary system energy balance obtained from available data on systems performances and operational conditions. MODENA calculates the mean temperature of primary sodium $\left(T_{\text {mean }}\right)$ at a given time $t$ by resolution of the following power balance equation:

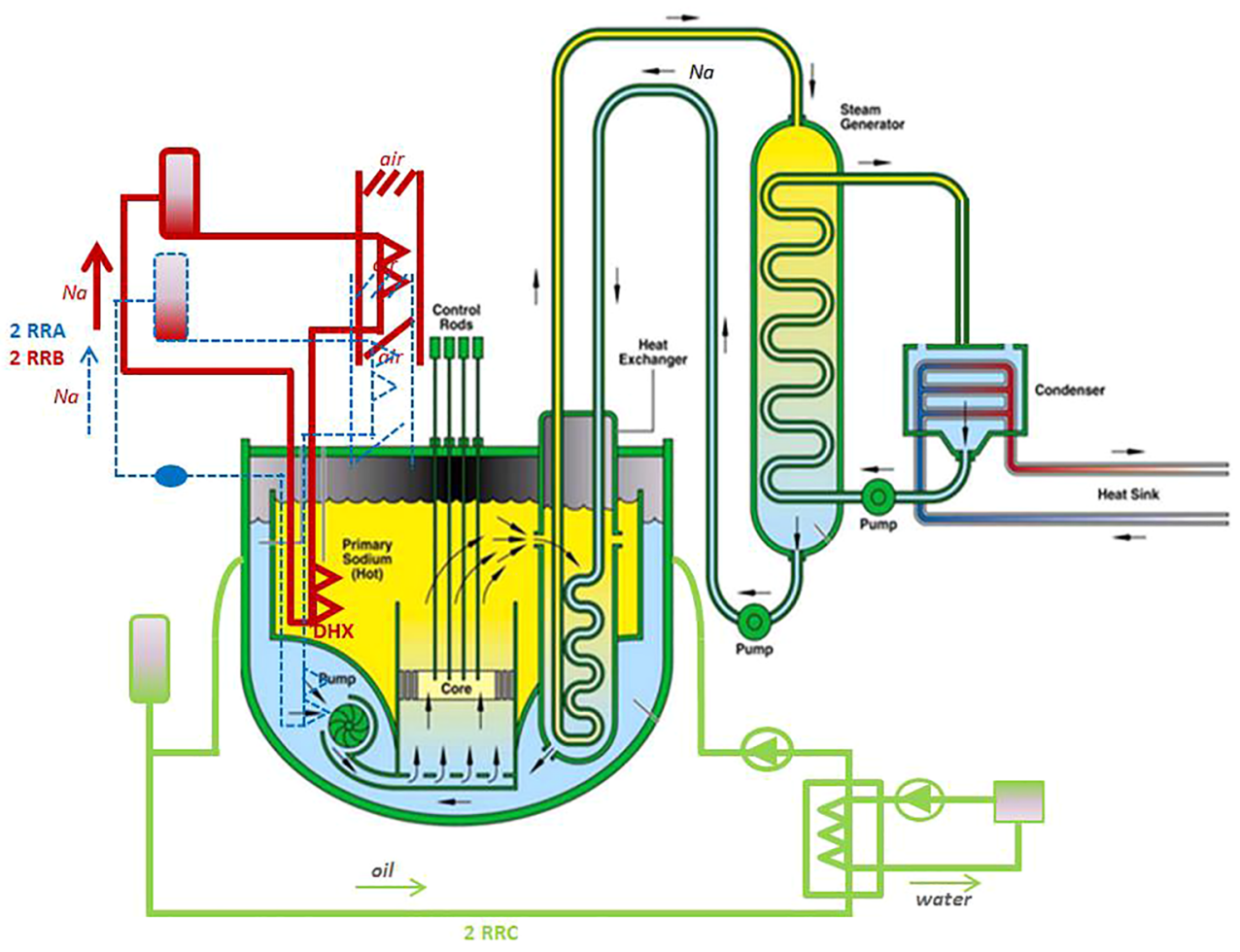

Fig. 2. Schematic description of ASTRID DHR systems (RRA: 2 active trains, RRB: 2 passive trains, RRC: 2 active trains, SCL: 4 normal active trains). 

where:

$I_{\text {mean }} \times \frac{d T_{\text {mean }}}{d t}=\left(D+P_{P P}+P_{S P}\right)-\left(P_{R R A}(\right.$ Tmean $)+P_{R R B}($ Tmean $)+P_{R R C}($ Tmean $\left.)\right)$

$I_{\text {mean }} \times \frac{d T_{\text {mean }}}{d t}=\left(D+P_{P P}+P_{S P}\right)-\left(P_{R R A}(\right.$ Tmean $)+P_{R R B}($ Tmean $)+P_{R R C}($ Tmean $\left.)\right)$

$\mathrm{I}_{\text {mean }}=$ mean thermal inertia of the system, $\mathrm{MJ} /{ }^{\circ} \mathrm{C}$

$\mathrm{T}_{\text {mean }}=$ mean primary sodium temperature, ${ }^{\circ} \mathrm{C}$

$\mathrm{D}=$ decay heat, MW

$\mathrm{P}_{\mathrm{PP}}=$ primary pumps power, $\mathrm{MW}$

$\mathrm{P}_{\mathrm{SP}}=$ secondary pumps power, $\mathrm{MW}$

$\mathrm{P}_{\mathrm{RRA}}\left(\mathrm{T}_{\text {mean }}\right)=$ power removed by RRA at $T_{\text {mean }}$ temperature, $\mathrm{MW}$

$\mathrm{P}_{\mathrm{RRB}}\left(\mathrm{T}_{\text {mean }}\right)=$ power removed by $\mathrm{RRB}$ at $T_{\text {mean }}$ temperature, $\mathrm{MW}$

$\mathrm{P}_{\mathrm{RRC}}\left(\mathrm{T}_{\text {mean }}\right)=$ power removed by $\mathrm{RRC}$ for a primary sodium tem-

perature at $T_{\text {mean }}$ temperature, $\mathrm{MW}$

The calculations confirmed that:

- the RRC system, as currently designed, is not sufficient to remove alone enough decay heat to bring the primary sodium temperature under $650{ }^{\circ} \mathrm{C}$ within a week and,

- one train of the RRA or RRB systems is sufficient to fulfill the decoupling criterion.

Fault tree modelling is based on conceptual design information, reliability data and common cause failures representation:

- The fault trees for Reactor Shutdown, Decay Heat Removal, Electric Power supply and Instrumentation and Control (I\&C) systems were developed using the available conceptual design information;

- Reliability data for the components failure rates and probabilities per demand were extracted mainly from the EG\&G database (INEL, 1990) for components specific to sodium fast reactor design and from NUREG/CR-6928 (NRC, 2007) for support systems components. Repairs were not considered;

- Common cause failures were modelled using the Multiple Greek Letters approach. No common cause failure is postulated between the DHR systems;

- Maintenance operations are modelled based on different assumptions:

- Preventive maintenance cannot concern more than one DHR train at the same time;

- The maintenance on a DHR train makes it unavailable for a week;

- Manoeuvrability tests and position verifications are performed for safety components after each intervention for maintenance;

- Human reliability was considered with an arbitrary and conservative probability of $10^{-1}$ for actions related to the recovery of I \&C failures when starting RRB system. For pre-accidental human errors connected to human interventions for maintenance, ASEP (Accident Sequence Evaluation Program; NRC, 1987) methodology was implemented with a mean probability of $3.10^{-2} / \mathrm{d}$, which is reduced by applying recovery factors when tests are operated after maintenance.
Event tree modelling relies on:

- Operational data;

- Postulated initiating events with their associated frequencies.

The list of considered initiating events was derived from the analysis of previous SFRs PSA's completed by master logic diagram implementation where the initiating events were classified into four main families. In a preliminary approach, the study was limited to 9 of these initiating events (IE), studied in power, and selected as representative of the different families in terms of accidental scenarios and frequencies:

- Spurious reactor shutdown (SRS, 1/yr);

- Trip of one primary pump (PP1, 5.10 $1 / \mathrm{yr}$ );

- Trip of all 3 primary pumps (PP3, $10^{-2} / \mathrm{yr}$ );

- Control rod withdrawal (CRW, $10^{-2} / \mathrm{yr}$ );

- Loss of off-site power $<2 \mathrm{~h}$ (LOOP $<2 \mathrm{~h}, 4.10^{-2} / \mathrm{yr}$ );

- LOOP > $2 \mathrm{~h}\left(4.10^{-3} / \mathrm{yr}\right)$;

- Loss of steam generator cooling (LSGC, $2.10^{-2} / \mathrm{yr}$ );

- Trip of all 4 secondary pumps (SP4, $10^{-2} / \mathrm{yr}$ );

- Inadvertent draining of all secondary loops (ID4, $10^{-4} / \mathrm{yr}$ ).

Two types of event trees were considered:

- The initiating events event trees (IEET); (see Fig. 3 by example)

- The generic DHR event tree (GET) (see Fig. 4).

The IEETs aim at characterizing the IEs in terms of frequency and impact on the availability of DHR systems to ensure decay heat removal. Each IEET includes the specificities of the corresponding IE, mentioned by means of a dedicated boundary condition set (BC set).

IEETs deal with reactivity control: when the reactivity control is satisfactory, the DHR consequence is the input for the GET. CD1 corresponds to core damage frequency when reactivity control has failed (unprotected sequences) (see Fig. 3).

The loss of off-site power IEs (LOOP $<2 \mathrm{~h}$ and LOOP $>2 \mathrm{~h}$ ) has been represented by the same IEET in which the probability of recovering the station service power $2 \mathrm{~h}$ after the occurrence of the IE is tested. The GET deals with decay heat removal. It is generic because it includes the three identified systems RRA, RRB, RRC and can be adapted to any IE.

In Table 2, the time period of $168 \mathrm{~h}$ is divided into two periods, [0, T1] and [T1, 168 h], to take into account 2 RRCs as an additional sufficient DHR system from T1, T1 depending on RRC performances. These two periods are illustrated in Fig. 4.

In 2015, the Core Damage Frequency (CDF corresponding to CD consequence) was evaluated for the 9 aforementioned selected representative initiating events (IE) on a time period of $168 \mathrm{~h}$ ( 1 week) for states in full power, and by considering the reference configuration of DHR systems.

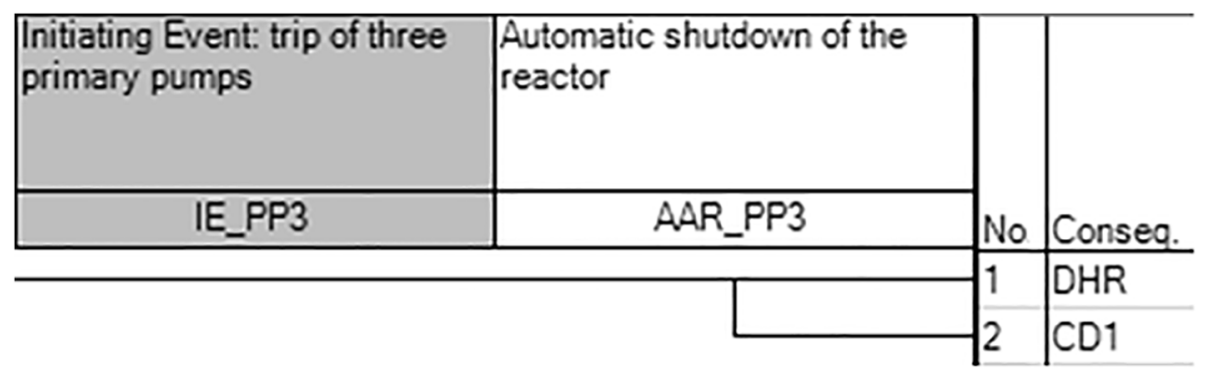

Fig. 3. Example of an IE event tree for the trip of all primary pumps. 
Table 2

DHR systems considered in the PSA for the DHR function in the different periods of time.

\begin{tabular}{lll}
\hline Configuration & $\begin{array}{l}\text { Success criteria on } 168 \mathrm{~h} \text { : minimum requirement systems } \\
\text { for PSA to respect the decoupling criteria }\end{array}$ \\
\hline Ref: 2 RRA, 2 RRB, 2 RRC & {$[0, \mathrm{~T} 1]$} & {$[\mathrm{T} 1,168 \mathrm{~h}]$} \\
& $1 \mathrm{RRA}$ & $1 \mathrm{RRA}$ \\
& Or 1 RRB & Or $1 \mathrm{RRB}$ \\
& & Or 2 RRC \\
\hline
\end{tabular}

In the same way as presented in (Curnier et al., 2014), different variants of configurations of the DHR function were evaluated and compared to the reference configuration in terms of resulting CDF, especially in order to quantify the impact of RRC system performance on $\mathrm{CDF}$.

\subsubsection{Illustration of the probabilistic assessment results for design and prospects}

Systems modelling allowed designers to check the correct application of deterministic design rules and to highlight the importance of support systems diversification. It was a way to improve the robustness of the DHR systems, by analyzing the preponderant minimal cut sets (MCS), and also the DHR function's robustness, by ensuring that it can be fulfilled correctly in any accidental condition during the required period.

In the reference configuration, the analysis of the main MCS for global CDF calculation highlighted the high contribution of the IE PP3 (74\% of the core damage frequency) and that, for two reasons:

- In case of IE PP3, the decay heat removal after shutdown can rely on RRB system only, as RRA can't operate without primary convection; - The value of $10^{-2} / \mathrm{yr}$ attributed to IE PP3 frequency is quite high.

Fig. 5 represents the relative global CDF (global CDF/(global CDF for IE PP3 $=10^{-2} / \mathrm{yr}$ )) as a function of the frequency of IE PP3. When the frequency of IE PP3 is below $10^{-3} / \mathrm{yr}$, it can be shown that the global CDF stabilizes at a value corresponding approximately to a hypothetical situation where RRA operation is not dependent on primary convection.

This further illustrates the limitations of a PSA at the early design phase, when the component are not yet well-known, their mechanical failures are difficult to quantify and the accessibility to input data is difficult. Further analysis is required in order to reduce the functional dependency of RRA on primary convection and to evaluate the frequency of IE PP3 more properly for a correct interpretation of the results.

From the variants of DHR configurations analysis (V1 to V6 in Fig. 6), the comparison of core damage frequencies is made with consideration of the uncertainties on reliability data and initiating events' frequencies. The green points represent the mean values and the red bars, the interval including $95 \%$ of the values. This allows analysts to gather variants with close $\mathrm{CDF}$.
Since reliability data come from generic databases and there is little information on the future components, it is difficult to conclude that one variant is larger than the other by a comparison of the mean values without moderating the conclusions by MCS analysis and uncertainty consideration.

Even if definitive input structuring data is not required in the early design stage, the proposed methodology of determination must be taken under consideration at an earlier stage in the process.

The definition of the decoupling criterion deserves careful attention in order to prevent over-conservatism with the respect to the mean primary sodium temperature and the subsequent demonstration of a practically eliminated situation for the loss of the DHR function. This links the loss of the DHR function to the overpass of the temperature criterion, without consideration of the exposure time of the structures in the reactor to a temperature higher than $650^{\circ} \mathrm{C}$. Therefore, another decoupling criterion is proposed for further dynamic studies. It allows consideration of the exposure time of the reactor's structures, and therefore the cumulated damage to the structures caused by excessive temperature. It evaluates the creep from the Larson-Miller relation (parameters based on RCC-MRx, 2015) and enables users to take into account the joint effect of structure's temperature and time, in the dynamic analysis. With this method, a damage-value $>1$ corresponds to the loss of the DHR function for this second criterion.

The whole period of time calculation is an important piece of input data which corresponds to the period when the loss of the DHR function can lead to overpassing the decoupling criteria. A methodology to evaluate this period of time calculation has been developed. Based on the RRC total repair assumption, it aims at defining, through thermalhydraulic calculations, the moment when the risk of loss of the DHR function no longer exists due to:

- RRC is sufficient to remove enough decay heat to keep the temperature of primary sodium under $650{ }^{\circ} \mathrm{C}$.

- The grace delay after RRC failure is compatible with repair times.

- The calculation of this time depends on the performances and on the time repairs of RRC.

\section{PSA to support the demonstration of practically eliminated situation for the prolonged loss of the DHR function}

\subsection{Definition}

According to the WENRA report, an accident sequence is practically eliminated if it "can be considered with a high degree of confidence to be extremely unlikely to arise".

In the present study, the situation to be practically eliminated is the prolonged loss of the DHR function. Theoretically, DHR function is mandatory to operate until thermal leakage is equivalent to the decay heat to be removed. Therefore, DHR systems must operate on periods equal to several months. However, under the assumption that RRC is entirely repairable, it can be considered that the loss of the DHR function is not valid from the moment when the repair of any RRC component failure is compatible with grace delay allowed to the reparation. This moment was assessed from MODENA calculations to be

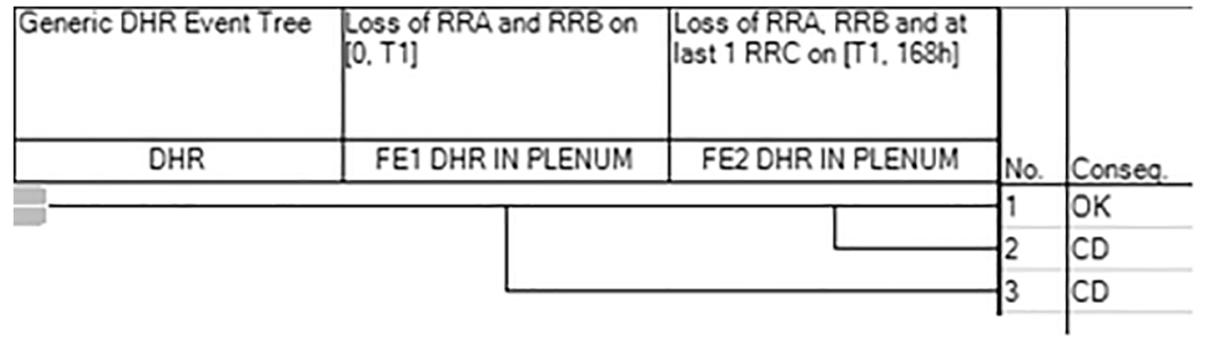

Fig. 4. Generic DHR event tree. 


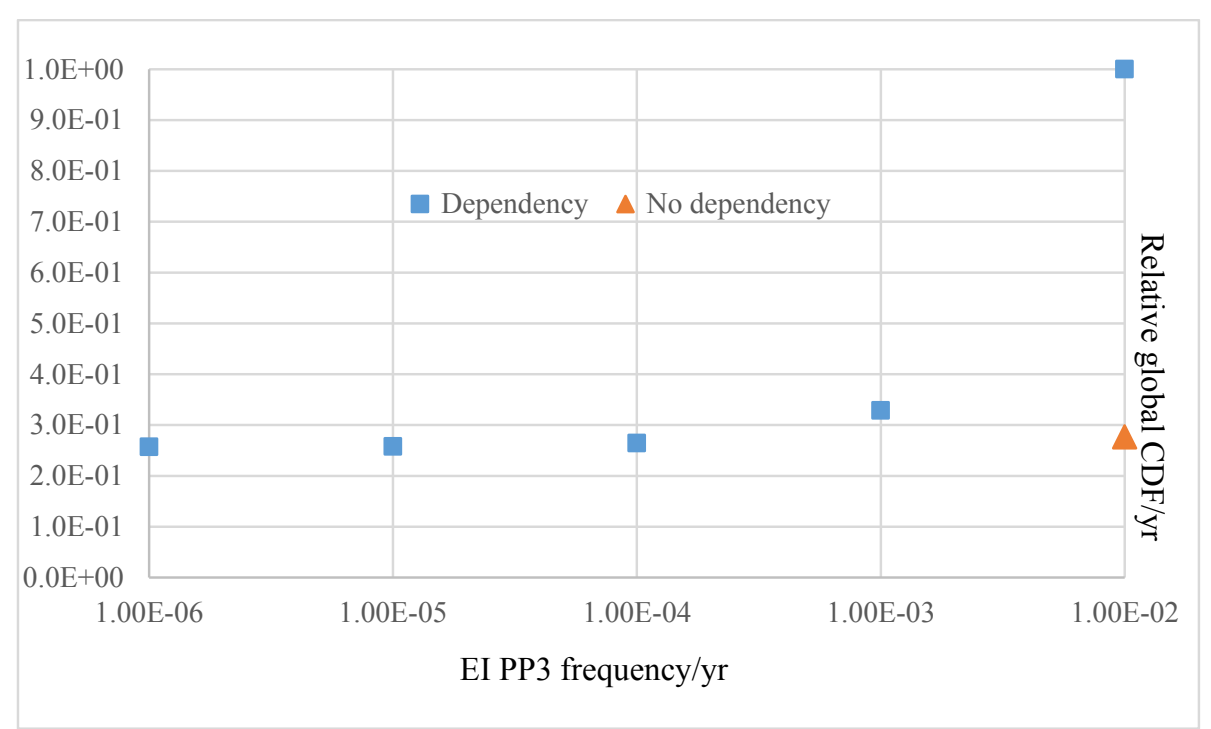

Fig. 5. Relative global CDF as a function of the frequency of the loss of primary pumping (functional dependency or not of RRA on primary pumping).

$3000 \mathrm{~h}$ after initiating event occurrence.

\subsection{Static approach limitations}

As the demonstration of practical elimination for the prolonged loss of DHR function is of capital importance for SFRs licensing, it must be performed with more realistic considerations than event trees/fault trees modeling can offer, especially on the long term (as far as time $>168 \mathrm{~h}$ ).

The static approach is conservative in that it doesn't allow to explicitly account for the timing/sequencing of events and system dynamics. If a system fails during a time period, this approach considers the failure from the beginning on this time period.

Furthermore, it is not possible to perform on line thermal-hydraulic calculations with Risk-Spectrum, what makes modelling by fault trees/ event trees inappropriate for temperature-conditioned repair consideration as it implies to be able to characterize the system at any time and assess if the grace delay is compatible with the repair time.

\subsection{Dynamic approaches based on reliability tool/thermal-hydraulic code coupling}

The ongoing second phase of the study is devoted to the evaluation of the probability of the loss of the DHR function over the long term for a configuration of the DHR systems which will make it possible to respect the 24-hours probabilistic target. This second phase is based on dynamic methods.

\subsubsection{Objectives of the dynamic approaches}

Dynamic approaches enable users to take into account not only the order of component failure but also the exact time of component failure and the time-dependent magnitude of the process variable, $T_{\text {mean }}$ in our case (Aldemir, 2013). Dynamic methods also aim at integrating the possibility of repairing failed components that can be salvaged, depending on their localization. Repairs will be easy if they concern a support system but almost impossible in acceptable repair times if they necessitate to drain a sodium circuit. These methods enable the evaluation of the primary sodium temperature at any moment as a function of DHR systems availability and then can determine if repair is possible or not by comparing the grace delay with repair times.

Where the first objective is to complete the static approach results over longer periods of time, these dynamic approaches will also offer the possibility of evaluating the DHR function over short periods but with less conservatism in considering all the DHR systems available.

The second objective consists in quantifying the risk associated with the loss of the decay heat removal function following the occurrence of initiating events.

\subsubsection{Dynamic approaches description}

Four dynamic approaches methodologies are being developed in a

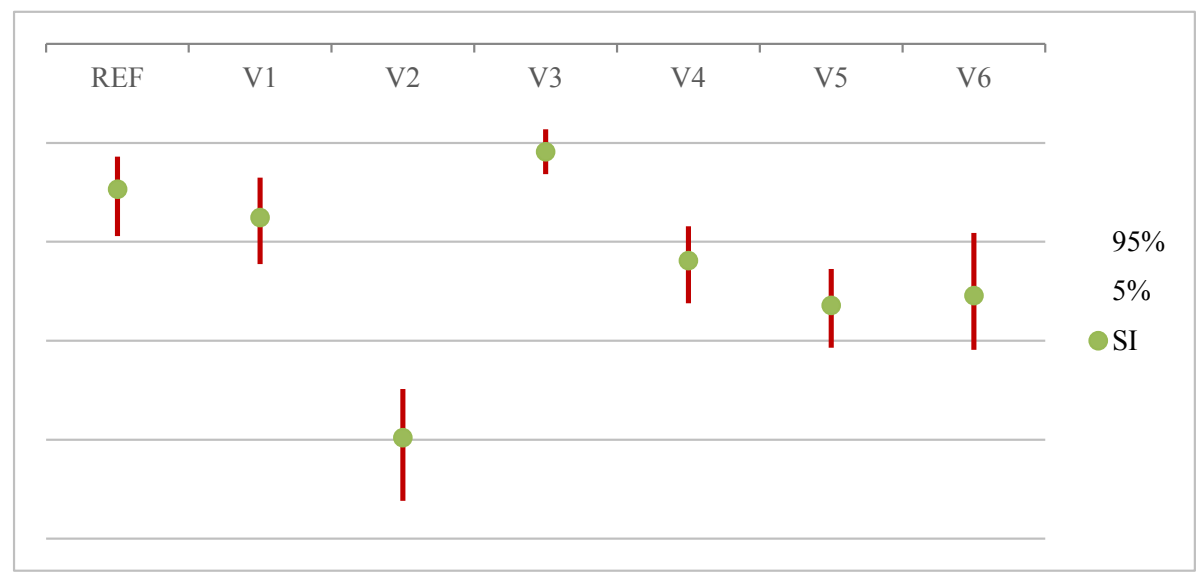

Fig. 6. Global CDF for different variants of DHR configurations analysis. 
prospective way by the CEA and its partners, FRAMATOME and EDF R\& D (Curnier et al., 2015).

Their common aim is to take into account the times of component failures and repairs, and their compatibility with the grace period, which is also time-dependent. The grace period is evaluated by the simplified thermal-hydraulic model (see Section 3.2.2) and Mean Down Times (MDT) are based on realistic assumptions. Three categories of failures are considered with regard to repair:

- Easily repairable

- Not-easily repairable

- Irreparable.

Note that an exponential mathematical law is used for repair modeling.

The principle of dynamic methodologies is to generate, for every considered IE, random sequences of failures and repairs of the available DHR systems. They are based on the same data as the fault trees/event trees modeling (see Section 3.2.2), except for repair times which are additional data depending on repair conditions. From the study of a required large number of random sequences of failures and repairs of the available DHR systems, it is then possible to estimate the probability of exceeding the decoupling criterion by the ratio of the number of the sequences leading to exceed the decoupling criterion and the total number of sequences.

Another interest of the dynamic approaches is to take into account (by a second loop of Monte Carlo simulation, for example) the uncertainties in a robust demonstration of practical elimination. The uncertainties may concern the input data of the thermal-hydraulic calculation, the reliability data and the repair data.

Among the four methodologies, two are being developed at CEA. Both utilize fault trees modelling:

- DayDREAM methodology proceeds from minimal cut sets of DHR fault trees including all the components of the main DHR circuits, the auxiliary circuits as well as all support systems (Marquès et al., 2015);

- EPSDYN consists of an automatic translation of the RISK-SPECTRUM model into a dynamic model, which is very interesting for a simple adaptation to design evolutions.
FRAMATOME is developing a model from Petri Nets divided into two complementary parts:

- A static model which does not change over time;

- Dynamic elements which inform us about the system's status at a given time.

At EDF R\&D, PyCATSHOO is a newly developed freeware tool used to evaluate the dynamic performance of a hybrid safety system that involves both the stochastic discrete behavior and continuous physical phenomena during a mission time. The dynamic performance is evaluated by the Piecewise Deterministic Markov Process (PDMP) in which two kinds of transitions (spontaneous and forced) may occur to be governed by discrete and continuous state variables, respectively (Chraibi, 2013; Rychkov and Chraibi, 2017; Davis, 1993; Yang et al., 1995).

These four dynamic methodologies are in the process of being validated on a simplified DHR design, for the demonstration of practical elimination of the loss of the DHR function.

Fig. 7 presents an example obtained by the first dynamic approach: the probability to lose the DHR function for the two decoupling criteria (see Section 3.2.3) is represented as a function of the MDT of situations not-easily repairable and for a mission time of $1000 \mathrm{~h}$.

All the results are normalized in relation to the value of probability obtained at $1000 \mathrm{~h}$ - when repair is impossible on the mission time with the sodium temperature criterion. Whatever the criteria, the longer is the MDT, the more improbable is the reparation and the higher is the relative probability to lose the DHR function. If not-easily repairable situations could be solved early, we would reduce the relative probability by one order of magnitude.

Moreover, Fig. 7 shows that calculations based on a damage criterion give lower probabilities to lose the DHR function than those obtained with the sodium temperature criterion. The ratio between both is of one degree of magnitude.

For a given required probability to lose the DHR function, this type of analysis will guide the choice of the acceptable MDT for situations not-easily repairable such as heat exchanger leakage.

\section{Conclusions}

With the goal of continuous improvement to the safety of ASTRID

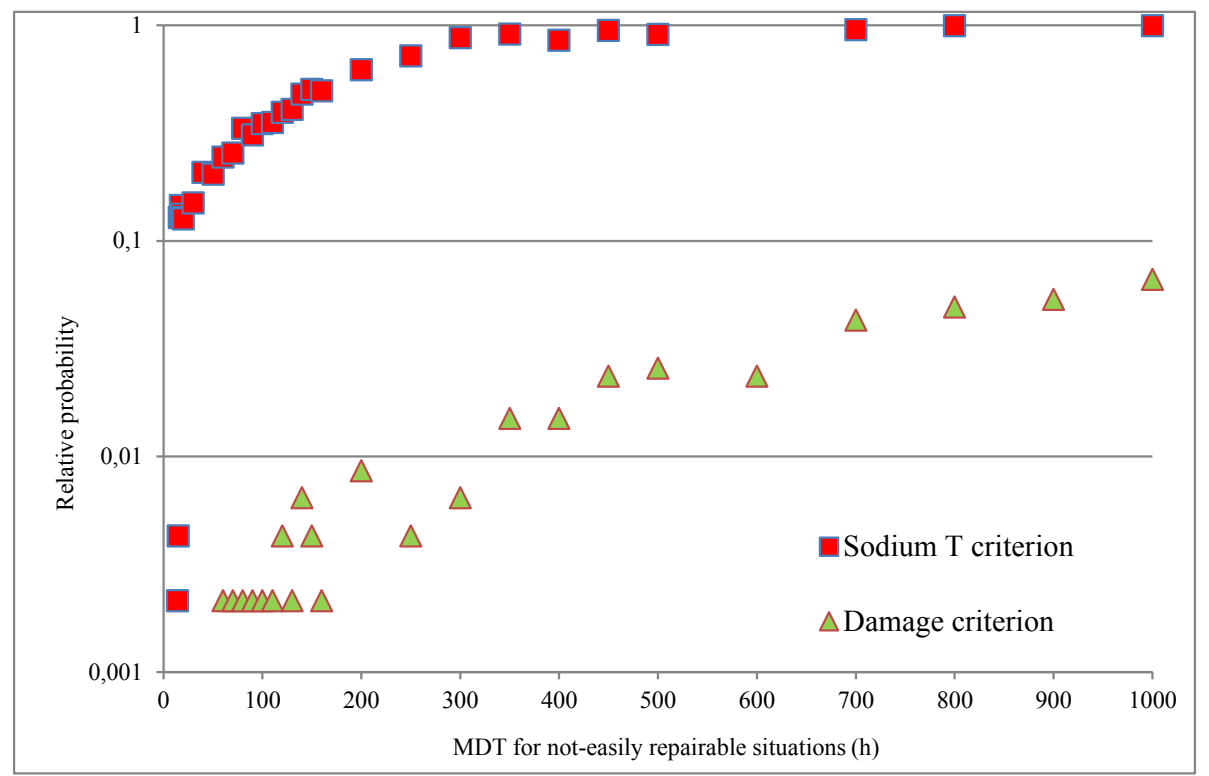

Fig. 7. Evolution of the normalized relative probabilities of the loss of the DHR function as a function of the MDT of not-easily repairable situations, for a mission time of $1000 \mathrm{~h}$. 
from the design phase, the deterministic approach has been completed by probabilistic studies dedicated to:

- Assessing design options and confirm the proper application of the deterministic design rules;

- Demonstrating the practical elimination of the loss of the Decay Heat Removal (DHR) function;

- Calculating the core damage frequency.

The ASTRID probabilistic assessment, initiated at the pre-conceptual design stage, has allowed researchers to:

- Check the independence between safety systems and in particular for DHR systems;

- Implement methodologies that lead to determining key input data (for example, the determination of the mission time of the DHR function is based on the assumption of total repair for RRC systems (cf. 3.2.3)) and to develop several dynamic methodologies for reliability evaluation of the DHR function. The dynamic probabilistic tools, which are in process of being validated, show already their powerful interest to build repairs strategy and to participate to the robust (considering uncertainties) demonstration of the practical elimination of the loss of the DHR function.

Probabilistic assessments for ASTRID illustrate the added value of combining probabilistic and deterministic approaches at the earliest stage of design. Deterministic rules remain the basis for a safe design and probabilistic assessments must be used when appropriate and cautiously with regards to its representativeness.

In closing, a PSA integrates so much data and so many parameters that the first assessments must be initiated at the very early design stage, in particular for the advanced reactors for which operational rules are quite uncertain. This leads to an awareness of the efforts required in performing the global probabilistic evaluation on time, developing methodologies if needed, and building a program of work that fits the objectives of the project.

\section{References}

Aldemir, T., 2013. A survey of dynamic methodologies for probabilistic safety assessment of nuclear power plants. Ann. Nucl. Energy 52, 113-124.

Arrêté INB de février 2012 - Available on: https://www.legifrance.gouv.fr/affichTexte. do? CidTexte $=$ JORFTEXT000025338573\&dateTexte $=20160205$.

Chraibi, H., 2013. Dynamic reliability modeling and assessment with PyCATSHOO: Application to a test case. In: Proc. Int. Conf. PSAM Tokyo, Japan.

Curnier, F., Gauthé, P., Quellien, P., Bertrand, F., Marquès, M., Gentner, H., Charrier, A.,
Vinçon, L., Jouve, S., Balmain, M., Rychkov, V., Banchieri, Y. Preliminary results from level 1 probabilistic safety assessment to support the ASTRID design. In: Proc. Int. Conf. ICAPP 2014, Charlotte, North Carolina, USA, 2014.

Curnier, F., Marquès, M., Kumar, R., Bama, Z., Rychkov, V., 2015. Symbiosis of static and dynamic probabilistic approaches to support the design process and evaluate the safety of SFR. In: Proc. Int. Conf. PSA 2015, Sun Valley, Idaho, USA.

Davis, M.H.A., 1993. Markov Models and Optimization. Chapman and Hall, London, UK.

EGG-SSRE-8875, 1990. Component Failure Data Base for Light Water and Liquid Sodium Reactor. INEL.

Gauché, F., 2013. The French Fast Reactor Program - Innovations in Support to Higher Standards FR13 Paper IAEA-CN-199-INV-062, March 5th.

Gauthé, P., Curnier, F., Bertrand, F., Gentner, H., Charrier, A., Balmain, M., Rychkov, V., Banchieri, Y., 2013. Level-1 PSA Studies for the ASTRID Reactor. In: Proc. Int. Conf. PSA 2013, Columbia, South Carolina, USA.

Gauthé, P., Curnier, F., Bertrand, F., Gentner, H., Charrier, A., Balmain, M., Rychkov, V.; Banchieri, Y., 2012. Use of Simplified Studies in Support of the ASTRID Design Process. In: Proc. Int. Conf. ICAPP 2012, Chicago, USA.

GIF, 2002. A Technology Roadmap for Generation IV Nuclear Energy Systems. USDOE and the Generation IV International Forum. Available on: https://www.gen-4.org/ gif/jcms/c 9502/generation-iv-goals.

IRSN report - Review of Generation IV Nuclear Energy Systems, 2015. http://www.irsn. fr/EN/newsroom/News/Documents/IRSN_Report-GenIV_04-2015.pdf.

Kubo, S., Kurisaka, K., Niwa, H., Shimakawa, Y., 2005. Status of conceptual safety design study of Japanese Sodium-cooled Fast Reactor. In: Proc. Int. Conf. GLOBAL 2005, Tsukuba, Japan.

Kurisaka, K., Sakai, T., Yamano, H., Fujita, S., Minigawa, K., Yamaguchi, A., Takata, T. 2014. Development of level-1 PSA method applicable to Japan sodium-cooled fast reactor. Nucl. Eng. Des. 269, 268-280.

Kurisaka, K., 2006. Probabilistic safety assessment of Japanese sodium cooled Fast Reactor in conceptual design stage. In: Proc. Int. Conf. Pacific Basin Nuclear Conference (PBNC-15), Sydney, Australia.

Marquès, M., Curnier, F., Gauthé, P., 2015. Consideration of physical behavior and possibility of repair in the long term reliability evaluation of decay heat removal systems. In: Proc. Int. Conf. PSA 2015, Sun Valley, Idaho, USA.

Modro, S. M., Bajs, T., Lyubarski, A., 2017. Defence in depth and practical elimination of early and large releases, concepts and practice. In: Proc. Int. Conf. Top safe 2017, Vienna, Austria.

NUREG/CR-4772, 1987. Accident Sequence Evaluation Program Human Reliability Analysis Procedure. Sandia National Laboratories, NRC.

NUREG/CR-6928, 2007. Industry-average Performance for Components and Initiating Events at US Commercial Nuclear Power Plants. NRC.

NUREG-75/014, 1975. WASH 1400. NRC.

RCC-MRx, 2015. Appendix A3.1S, Design and Construction Rules for Nuclear Installations Mechanical Components, edition AFCEN 2015 http://www.afcen.com/fr/ publications/rcc-mrx.

Rychkov, V., Chraibi, H. Dynamic probabilistic risk assessment at a design stage for a sodium fast reactor. IAEA-CN245-042, Fast Reactors, 2017.

Scandpower, member of Lloyd's register group: http://www.riskspectrum.com.

Vasile, A. https://www.iaea.org/NuclearPower/Downloadable/Meetings/2015/2015-05 25-05-29-NPTDS/Country/7_ASTRID_project_TWG_FR_MAY_2015.pdf.

WENRA report: Safety Objectives for New Nuclear Power Plants, March 2013 - Available on: http://www.wenra.org/media/filer_public/2013/08/23/rhwg_safety_of_new npp_designs.pdf.

Yamano, H., Kubo, S., Shimakawa, Y., Fujita, K., Suzuki, T., Kurisaka, K., 2012. Safety design and evaluation in a large-scale Japan sodium-cooled fast reactor. Sci. Technol. Nucl. Installat.

Yang, Y.Y., Linkens, D.A., Banks, S.P., 1995. Modelling of hybrid systems based on extended coloured petri nets. In: Antsaklis, P. (Ed.), Hybrid Systems-II, pp. 509-528. 